\title{
Residential accessibility's relationships with crash rates per capita
}

\section{Louis A. Merlin}

Florida Atlantic University

Imerlin@fau.edu

Chris R. Cherry

University of Tennessee, Knoxville

cherry@utk.edu

\author{
Amin Mohamadi-Hezaveh \\ University of Tennessee, Knoxville \\ amohamad@vols.utk.edu
}

Eric Dumbaugh

Florida Atlantic University

edumbaug@fau.edu
Abstract: This paper examines the relationship between residential accessibility, i.e., accessibility from a person's home address, and their likelihood of being in a crash over a three-year period. We explore two potential relationships with accessibility. The first is that persons who live in areas with high destination accessibility may drive less and therefore are less likely to be in vehicular crashes. The second is that persons who live in high vehicle miles traveled (VMT) accessibility areas may be exposed to higher levels of traffic in their regular activity space and therefore may be more likely to be in crashes of all modal types. Examining traffic analysis zones in Knoxville, Tennessee, this research finds some evidence for each of these hypothesized effects. These oppositely directed effects have dominant influence within different travel-time thresholds. The first relationship between destination accessibility and fewer crashes is found to be strongest for 10-minute auto accessibility, whereas the second relationship between VMT accessibility and more crashes is found to occur at 10 -minute, 20-minute, and 30-minute thresholds.

\section{Introduction}

Accessibility is a concept on the rise in transportation planning. Accessibility is defined as ease of access to destinations, either for a particular person (person-based accessibility) (Miller, 1991) or for a particular place (place-based accessibility) (Handy \& Niemeier, 1997). A growing chorus of transportation researchers and analysts are advocating for accessibility as a primary measure in transportation performance evaluation, for transportation plans (Chicago Metropolitan Agency for Planning, 2008), as well as for

\section{Article history:}

Received: June 27, 2019

Received in revised form:

February 5, 2020

Accepted: February 7, 2020

Available online: May 22, 2020

Copyright 2020 Louis A. Merlin, Chris R. Cherry, Amin Mohamadi-Hezaveh \& Eric Dumbaugh http://dx.doi.org/10.5198/jtlu.2020.1626

ISSN: 1938-7849 | Licensed under the Creative Commons Attribution - Noncommercial License 4.0

The Journal of Transport and Land Use is the official journal of the World Society for Transport and Land Use (WSTLUR) and is published and sponsored by the University of Minnesota Center for Transportation Studies. 
individual transportation projects (Merlin, Levine, \& Grengs, 2018; Virginia Department of Transportation, 2017).

There is a fair amount of confusion about the accessibility concept, both in transportation planning practice and in research (Boisjoly \& El-Geneidy, 2017). Access to transportation infrastructure, as measured through items such as distance to bus stops, is not equivalent to the concept of access to destinations, which is the primary and dominant meaning of accessibility. It is access to destinations measures that have been demonstrated to have a great deal of correlation with travel behaviors (Ewing \& Cervero, 2010; Owen \& Levinson, 2015) as well as other outcomes such as land development and property values (Heyman, Law, \& Berghauser Pont, 2018; Waddell, 2002). Access to transportation infrastructure, while also perhaps important, is conceptually distinct, and generally should not be equated with the transportation planning concept of access to destinations (Geurs \& Van Wee, 2004; Handy \& Niemeier, 1997; Hansen, 1959).

A significant body of research covers the relationship between the built environment and safety (Ewing \& Dumbaugh, 2009; Stoker et al., 2015); however, as of this writing, we are not aware of any peer-reviewed published research into the intersection between accessibility to destinations and roadway safety. A paper by Kim et al. titled "Accessibility and Accidents" covers the topic of the presence of transportation infrastructure, and in fact includes no access to destination measures in its analysis (Kim, Pant, \& Yamashita, 2010). Accessibility is different from most measures of the built environment such as density, land-use patterns, street network design, and roadway design in that it is not an internal measure. Rather, place-based accessibility is typically a measure of the relationship of a particular zone's geographic arrangement relative to other zones and the destinations they contain. In other words, it is a reflection of relative regional location in relation to transportation infrastructure and land-use patterns rather than a descriptor for the internal built environment of the zone.

This paper examines the relationship between residential accessibility (i.e., the level of accessibility where people reside) and the likelihood of being in a crash over the course of three years. The focus on residential locations, rather than crash locations, is that the link between household travel behavior and accessibility is focused on the accessibility present at persons' residential location (Ewing \& Cervero, 2010). The objective of the paper is to understand whether interventions that improve destination accessibility, which is its own important objective in transportation planning, either increase or decrease the number of crashes that are likely to occur for the population living in that area. Policy prescriptions for increasing accessibility, such as promoting denser development in high accessibility areas, or improving transportation infrastructure in those areas with a significant but underserved population, may incidentally increase or decrease the traffic safety of the built environment.

The theoretical relationship between accessibility and safety is two-fold, with each potential effect working in the opposite direction. Accessibility has been related to reduced vehicle miles traveled for households, with the relationship being stronger than other built environment variables such as density (Ewing \& Cervero, 2010; Stevens, 2016). Therefore, if persons who live in high accessibility places drive less, they should have lower vehicular exposure and experience fewer vehicular crashes per year. This is quite similar to the relationship that has been established between sprawl and crashes in some previous research (Ewing, Hamidi, \& Grace, 2016a; Marshall \& Garrick, 2011). If such a relationship exists, it would be mediated by the amount of vehicular travel conducted by each household (See upper section of Figure 1).

The second half of the potential relationship between accessibility and safety concerns broader patterns in the background environment rather than household travel behavior. The more vehicles on the street in the built environment, the greater the amount of background traffic that exists in and around their activity space (Marshall \& Garrick, 2011; Quddus, 2008). Each vehicle mile on the street system is a potential source of conflict for a crash. This accessibility metric weights the presence of vehicles in a 
way that reflects their geographic sphere of influence, therefore creating a proxy measure for the amount of ambient traffic surrounding a given household's residential environment. As the level of ambient traffic rises, that household's crash risk is increased (See lower section of Figure 1).
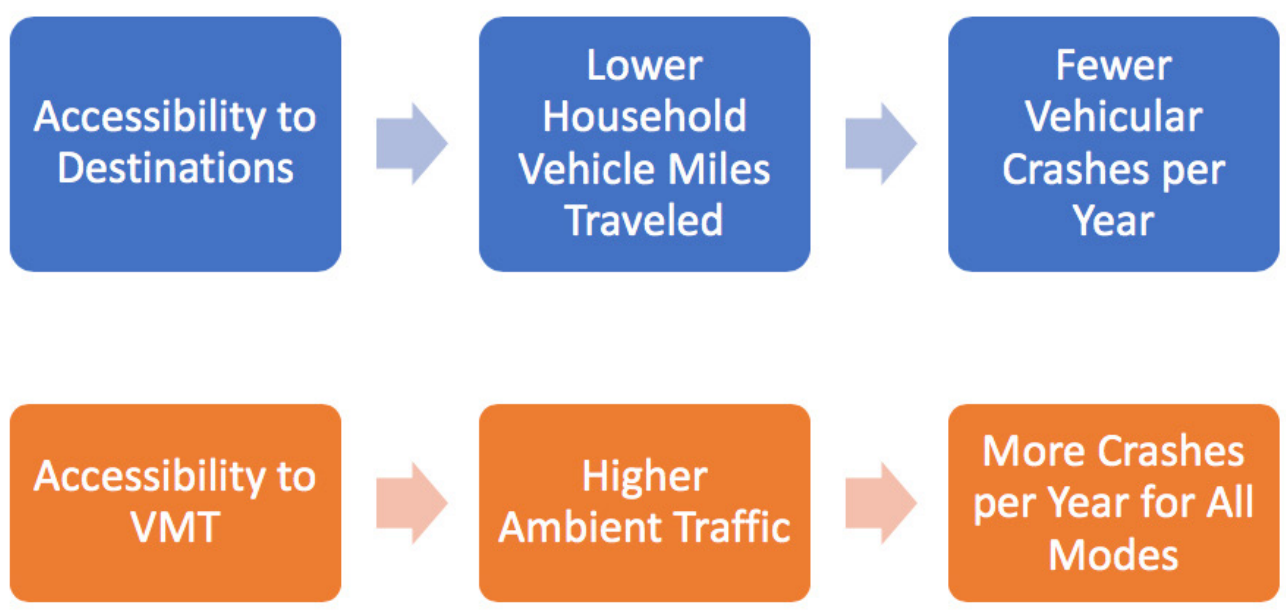

Figure 1. Two theoretical relationships between residential accessibility and crashes

\section{$2 \quad$ Literature review}

The built environment can influence both the likelihood and the severity of a crash occurring at a particular location. There are several studies and literature reviews that extensively cover the influence of the built environment on crashes (Ewing \& Dumbaugh, 2009; Retting, Ferguson, \& McCartt, 2003; Rothman, Buliung, Macarthur, To, \& Howard, 2014; Stoker et al., 2015). Studies to date have addressed issues such as where hot spots of crashes occur (Wier, Weintraub, Humphreys, Seto, \& Bhatia, 2009), the influence of the built environment on the severity of pedestrian and bicycle crashes (Chen \& Shen, 2016), and how various roadway design characteristics affect roadway crash rates (Abdel-Aty et al., 2009).

The effect of a traveler's residential location on their likelihood of being in a crash has not been studied as thoroughly. Historically, most safety analysis focuses on crash locations because of the proximate causes present at the crash site. Also, crash data generally includes descriptive details of the built environment surrounding the crash location. The link between the built environment at a traveler's residential location and the likelihood of traffic crashes may not be obvious at first since the residential location of a person is not necessarily where their crashes occur. However, there is an extensive literature on how the residential built environment influences travel behavior (Ewing \& Cervero, 2010; Stevens, 2016), and travel behavior may in turn influence both exposure and crash risk. We categorize research that analyzes residential locations and their characteristics as explanatory factors related to traffic crashes as "home-based analysis" or HBA (Hezaveh, Arvin, \& Cherry, 2019).

Ewing and Dumbaugh (2009) posit that one of the ways that the residential built environment may influence the likelihood of being in a crash is via exposure. Certain residential built environments are associated with increased travel exposure, i.e., higher vehicle miles traveled, and therefore increased 
probability of being in a vehicular crash. Indeed, the divergence in crash fatalities per capita and crash fatalities per mile illustrates that countries with more vehicular travel experience a higher number of crash fatalities in part due to higher rates of vehicular travel (OECD \& ITF, 2016). For example, even though the US is only 1.86 times riskier on a per-mile basis than the UK, it is 3.52 times riskier (or about $1.89 \mathrm{x}$ more) on a per-capita basis, due to the larger amounts of per-capita vehicular travel in the US. Therefore, greater vehicular travel in the US is associated with higher probability of being in a crash at the national level; it is logical to extrapolate this trend and assume that greater vehicular travel would be associated with higher probability of being in a crash on the subnational level as well, with high-VMT residential locations being associated with more vehicular crashes while low-VMT residential locations would be associated with fewer.

Several papers examine the relationship between sprawl or compactness and crashes. Presumably, those who live in more sprawling environments drive more and are therefore more subject to being in a crash. Ewing, Hamidi, and Grace (2016b) find that sprawling counties are associated with more fatal crashes, but fewer injury crashes, than more compact counties. Mohamed, vom Hofe, and Mazumder (2014) find that greater jurisdictional sprawl is inversely related to the number of fatal and injury crashes, though they do not take into account the potential spillover effect, i.e., crash locations rather than residential locations are the object of their analysis. Lucy (2003) conducts a study comparing the risk of death in a traffic crash with the risk of death by murder, examining data at city, county, state, and federal levels. He finds that traffic fatality rates are highest in exurban areas and outer counties as compared with inner counties. Yeo, Park, and Jang (2015) conduct a path analysis of the relationship between sprawl, VMT, traffic fatalities, income, and fuel cost for 147 urbanized areas in the US. They find that sprawl has both a direct effect increasing total traffic fatalities and an indirect effect increasing traffic fatalities through increased VMT per capita. In summary, the literature suggests that built environments associated with higher VMT are associated with more traffic fatalities; however, these environments are not consistently associated with more traffic injuries as well.

As mentioned above, the literature on residential built environments and the likelihood of being in a crash has focused on the complex, multidimensional construct of sprawl. However, the literature on the built environment and travel behavior distinguishes between several different measurable dimensions that each influence travel behavior: density, design, diversity, and destination accessibility (Ewing \& Cervero, 2010). The advantage of focusing on these individual dimensions is that they are more readily measurable and less abstract than multi-dimensional sprawl. They can also be measured at finer scales than the county level, such as the Census Block Group or Traffic Analysis Zone (TAZ). This allows for neighborhood-level of spatial analysis of built environment features related to travel behavior.

Evidence suggests that the single most important variable related to reduced vehicle miles traveled is destination accessibility (Ewing \& Cervero, 2010; Stevens, 2016). Therefore, this paper examines the relationship between such accessibility and crashes, based on the hypothesis that those who live in areas of high accessibility will engage in less vehicular travel and therefore experience reduced rates of vehicular crashes on a per-capita basis.

Although accessibility has not been the direct object of investigation in any traffic safety studies we are aware of, accessibility-like measures have been used as proxy measures of exposure in some past research. For example, Marshall and Garrick (2011) employ simplified gravity-based measures of proximity to population and employment as an exposure measure. Likewise, Quddus (2008) applies a gravity measure of the availability of vehicles in nearby wards as an exposure variable. Therefore, the concept that accessibility measures can be used as measures of exposure is not entirely new but has not been systematically studied.

This paper breaks ground in several ways. First, two distinct hypotheses relating how residential 
accessibility may affect crash rates are articulated and tested (See Figure 1). Second, a variety of accessibility measures taking into account different travel time thresholds and varying destinations types are examined. The result is the first paper to systematically examine the relationship between residential, place-based accessibility and crash rates per capita in a residential district or zone.

\section{Data and methods}

In this study, we conduct a home-based analysis (HBA) of the relationship between residential accessibility, other built environment variables, socio-demographic variables, and crash rates at the zonal level. Accessibility data, built environment data, and socioeconomic data are from the 2014 Knoxville Regional Travel Demand Model (KRTM). Figure 2 displays the Knoxville region study area that includes Knox, Anderson, Roane, Union, Grainger, Jefferson, Sevier, Blount, and Loudon counties in Tennessee.

Table 1 presents the descriptive statistics of the available variables for TAZs. Variables available at the TAZ level include demographic, built environment, and employment variables. Demographic variables include population, number of households, average household size, median household income, workers per household, vehicles per household, total vehicles, students per household, percentage of households with seniors, K-12 school enrollment per zone, and college enrollment per zone. Built environment variables include land area, percent of parking that is paid, percentage of linear street miles with sidewalk coverage, population density per square mile, and employment density per square mile. Employment data includes total employment, basic employment, industrial employment, retail employment and service employment.

The Knoxville Regional Travel Model (KRTM) has a hybrid activity-based/four-step design using elements of activity-based model architecture for trip generation. The model creates a synthetic disaggregate population of households for the region derived from Census demographic information and allocates this population to traffic analysis zones (TAZs). More information about the Knoxville Regional Travel Demand Model is available from its official report (Lochmueller \& Associates, 2012). The modeling area contains 1186 TAZs, and the model provides data on the socio-demographics and built environment for each TAZ.

We calculated cumulative-opportunity vehicular accessibility measures for each TAZ with travel times based upon AM peak-hour travel times. These figures include accessibility to employment, accessibility to total population, accessibility to VMT, and accessibility to specific types of employment. We extracted KRTM origin-destination shortest-path travel times between zones and then calculated accessibly within 10, 20, and 30 minutes from TAZ centroids. The equation for cumulative-opportunity accessibility is provided in equation (1) below.

$$
A_{i}^{k}=\sum_{j} J_{i}^{k} I\left(t_{i j}\right) \text { where if } t_{i j} \leq T \text { then } I\left(t_{i j}\right)=1 \text { else } I\left(t_{i j}\right)=0
$$

Where $A_{i}^{k}$ is the accessibility from zone $i$ to jobs of type $k, J_{j}^{k}$ is the number of jobs of type $k$ in zone

$\mathrm{j}$, $\mathrm{t}_{\mathrm{ij}}$ is the shortest path vehicular travel time from zone $\mathrm{i}$ to zone $\mathrm{j}$, and $\mathrm{I}()$ is the indicator function for a given travel time threshold $\mathrm{T}$.

Table 2 presents descriptive statistics for various TAZ accessibility measures for three travel time thresholds, 10-minute, 20-minute, and 30-minute for auto travel. The "destination" variables examined for accessibility include population, various types of employment, and vehicle miles traveled (in 100,000s) calculated for each destination's zone. As expected, accessibility becomes systematically larger 
at the larger travel time thresholds. Accessibility for specific kinds of employment is smaller than for overall employment.

Figure 2 shows 10-minute accessibility to total employment by auto during the AM peak period for all TAZs in the Knoxville Regional Travel Model area. Downtown Knoxville shows the highest employment accessibility, but several other regional centers are also concentrations of auto accessibility to employment. Accessibility tends to decrease gradually outwards from these regional subcenters.

Table 1. Socio-demographic and built environment variables for Knoxville TAZs with population >=100

\begin{tabular}{lccc}
\hline \multicolumn{1}{c}{ Variable } & Mean & Std. Dev. & Max \\
\hline Area (Square Miles) & 3.41 & 6.43 & 104.59 \\
Population & 1015.12 & 750.39 & 5053.00 \\
Number of Households & 411.12 & 306.98 & 2095.00 \\
Average Household Size & 2.41 & 0.31 & 3.29 \\
Median Household Income & 46654.80 & 21075.42 & 168227.00 \\
Workers per Household & 1.21 & 0.24 & 2.10 \\
Vehicles per Household & 1.86 & 0.36 & 2.69 \\
Students per Household & 0.39 & 0.18 & 1.11 \\
Percent of Households with Senior (65+) & 0.28 & 0.10 & 0.72 \\
K-12th grade school enrollment & 144.90 & 365.79 & 3210.00 \\
Percent UT off-campus students in resi-dence & 0.02 & 0.042 & 0.75 \\
College/University Enrollment & 31.78 & 354.55 & 8900.00 \\
Basic Employment & 37.06 & 68.18 & 1124.00 \\
Industrial Employment & 69.40 & 279.84 & 5247.00 \\
Retail Employment & 92.12 & 207.44 & 1924.00 \\
Service Employment & 200.78 & 348.63 & 4938.00 \\
Total Employment & 399.37 & 587.60 & 5997.00 \\
Percent Pay Parking & 0.00 & 0.03 & 0.39 \\
Percentage of Sidewalk Coverage & 0.21 & 1.00 \\
Vehicles & 787.91 & 0.32 & 4101.11 \\
Population Density per Square Mile & 1377.27 & 606.89 & 101778.00 \\
Employment Density per Square Mile & 1014.66 & 2736.12 & 4538.47 \\
\end{tabular}


Table 2. Accessibility distribution for TAZs with population $>=100$

\begin{tabular}{|c|c|c|c|c|c|}
\hline Variable & $\begin{array}{l}\text { Distance } \\
\text { (minutes) }\end{array}$ & Mean & Std. Dev. & Min. & Max. \\
\hline \multirow[t]{3}{*}{ Population } & 10 & 27452 & 24937 & 115 & 117693 \\
\hline & 20 & 139454 & 107219 & 262 & 394136 \\
\hline & 30 & 314692 & 186948 & 1668 & 624610 \\
\hline \multirow[t]{3}{*}{ VMT_FA (Freeway and Arterial)* } & 10 & 50.21 & 47.61 & 0.00 & 251.95 \\
\hline & 20 & 271.17 & 201.47 & 0.00 & 771.81 \\
\hline & 30 & 617.85 & 342.51 & 0.00 & 1171.49 \\
\hline \multirow[t]{3}{*}{ VMT_L (Local)* } & 10 & 12.31 & 11.29 & 0.00 & 54.44 \\
\hline & 20 & 73.98 & 47.47 & 0.06 & 192.87 \\
\hline & 30 & 50.21 & 47.61 & 0.00 & 251.95 \\
\hline \multirow[t]{3}{*}{ Basic Employment } & 10 & 1188 & 1182 & 0 & 6116 \\
\hline & 20 & 5695 & 4227 & 15 & 15425 \\
\hline & 30 & 12621 & 7283 & 54 & 24489 \\
\hline \multirow[t]{3}{*}{ Total Employment } & 10 & 20212 & 24038 & 4 & 116662 \\
\hline & 20 & 88197 & 77511 & 17 & 256109 \\
\hline & 30 & 184731 & 117116 & 97 & 359963 \\
\hline \multirow[t]{3}{*}{ Industrial Employment } & 10 & 2834 & 3236 & 0 & 15753 \\
\hline & 20 & 13127 & 9911 & 0 & 36768 \\
\hline & 30 & 27848 & 16343 & 3 & 56362 \\
\hline \multirow[t]{3}{*}{ Retail Employment } & 10 & 4287 & 4619 & 0 & 21980 \\
\hline & 20 & 19316 & 16517 & 0 & 56379 \\
\hline & 30 & 40765 & 24940 & 5 & 76532 \\
\hline \multirow[t]{3}{*}{ Service Employment } & 10 & 11903 & 15888 & 2 & 73840 \\
\hline & 20 & 50059 & 47544 & 2 & 147537 \\
\hline & 30 & 103498 & 69228 & 35 & 203492 \\
\hline
\end{tabular}

* This is daily vehicle mile traveled in one TAZ divided by 100,000

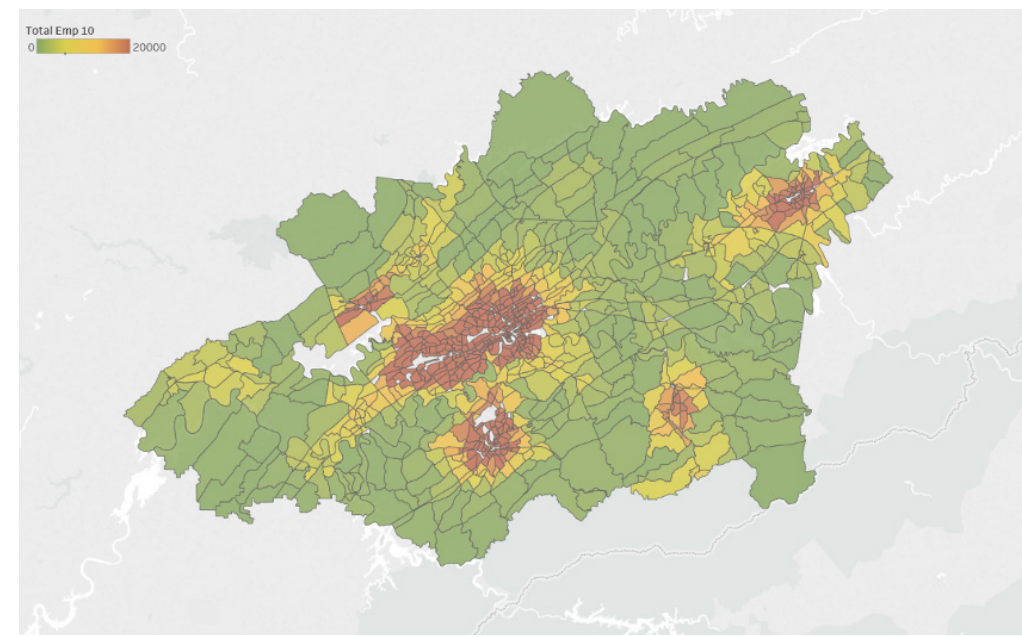

Figure 2. 10-minute employment accessibility by auto for the Knoxville study area TAZs 
Crash data are from the Tennessee Integrated Traffic Analysis Network (TITAN), a portal provided by Tennessee Highway Patrol (THP), which complies crash reports from law enforcement agencies. Between 2014-2016, the TITAN records included of 694,276 crashes and information for 2,026,666 individuals who were involved in these traffic crashes. Each record includes information about the roaduser type (i.e., driver, motorcyclist, passenger, pedestrian, bicyclist, vehicle's owner, witness, property owner, etc.), coordinates of the crash, and addresses of the individuals who were involved in traffic crashes.

Crashes were then tallied at residential TAZs using residential addresses and converted into a per capita measure. We excluded TAZs with a population of fewer than 100 individuals, since their crash counts per capita were not reliable, i.e., crash counts per capita can be unreasonably high or variable when the TAZ population is low. To count crashes at residential locations ( $\mathrm{n}=1,615,374$ across all modes), we used the Bing application program interface (API) services to geocode the addresses. The quality of the geocoding was checked by controlling for the locality of the addresses. Only those records that had an accuracy level of premises (e.g., property name, building name), address-level accuracy, or intersection-level accuracy were used for the analysis. 1,521,583 (94\%) records met the minimum address quality filter. Of those, 184,240 (12\%) addresses were located outside the KRTM analysis area. Table 3 shows descriptive statistics for the number of crashes by user type and by injury severity across TAZs for those TAZs with at least 100 residents. Driver crashes only count crashes involving vehicular drivers at the location of the driver's residential address. We conduct separate analyses of vehicular crashes (Table 4) and total crashes (Table 5).

Table 3. Crash rates per capita for Knoxville TAZs, 2014-2016 ( $\mathrm{n}=988)$

\begin{tabular}{lcc}
\hline & \multicolumn{2}{c}{ Crash Rate (per 1000 population) } \\
\hline Safety Outcome & Rate & Standard Deviation \\
All Users Type & 247.3 & 937.8 \\
Driver Crashes & 180.2 & 691.1 \\
Killed or Severely Injured (KSI) & 15.7 & 67.5 \\
Minor and No Injury Crashes & 221.9 & 835.9 \\
\hline
\end{tabular}

As mentioned in the introduction, accessibility to destinations is expected to have a negative relationship with vehicular crashes per capita (See Figure 1). Accessibility to destinations here is operationalized as cumulative opportunity accessibility by automobile to work locations during the peak morning hour of travel. Travel time thresholds of 10, 20, and 30 minutes are examined. Among travel purposes, work-related travel is a minority of travel. However, many other types of travel also find destinations where workers of a particular type are congregated. Shopping trips tend toward destinations where retail jobs are present; Educational trips tend towards destinations where education jobs are present; and so forth. Because of this, job-based accessibility is sometimes used as a measure of generalized access to destinations, especially for retail or service industries (Ahlfeldt, 2011). In addition, we examine access to retail jobs and access to service jobs as alternative measures for the access-to-destinations construct.

Accessibility to the vehicle miles traveled (VMT) is expected to have a positive relationship with total crashes per capita inclusive of all travel modes (See Figure 1). Accessibility to the VMT is here operationalized as accessibility to total vehicle miles traveled on freeways and arterial streets (VMT_FA) or accessibility to total vehicle miles traveled on local streets by automobile during the peak morning hour of travel. Travel time thresholds of 10, 20 and 30 minutes are examined. 
Because various measures of accessibility are often strongly correlated, these hypothesized influences may be counterbalancing and therefore harder to discern. Although accessibility to employment and accessibility to vehicle miles traveled measure differing effects, they are typically highly correlated. For example, 10-minute VMT_FA accessibility and 10-minute employment accessibility are correlated $\sigma=0.874$ while 30 -minute VMT_FA accessibility and 30-minute employment accessibility are correlated $\sigma=0.960$.

We include a range of built environment and socio-demographic variables as controls. We measure built environment variables at the residential location of the crash victim, not the location of the crash, and therefore traditional built environment measures such as roadway length and classification are not likely to be influential. Rather, variables that influence the travel behavior of residents are more relevant. The percentage of parking that is paid for reflects parking scarcity in a household's home district, and therefore the likelihood that they own fewer vehicles than a typical household. The percentage of sidewalk coverage, on the other hand, corresponds with a greater likelihood of selecting walk mode for trips. The socio-demographic control variables are those that are also likely correlated with the amount of travel demand. Vehicles per population is a predictor of the amount of local vehicular use. Likewise, household income is a predictor of the amount that vehicles are used, because high-income households have higher VMT (Santos et al., 2011). University students are less likely to own vehicles, and less likely to drive them as much. Senior households are also likely to drive less and travel less by other modes as well. Other demographic variables were available, but we confined our analysis to those variables that had a theoretical expectation of influencing the amount of driving or other types of travel activity.

The dependent variable is crashes per capita because residential locations with more people will prima facie have their residents in more crashes. The question investigated here is that given a particular level of population, how likely is that population to be in a crash over three years given the built and socio-demographic environment of their residential area.

We examined many models but present 15 here. The five models of vehicular crashes per capita explore the effect of employment accessibility at different travel time thresholds and examine the effect of accessibility with and without other built environment control variables. Non-work trips are more likely to be made to retail and service destinations, and therefore we examine accessibility to retail and service employment here as well. There are five models of total crashes per capita as well, inclusive of nonvehicular crashes such as pedestrian and cyclist crashes. We examine three levels of accessibility threshold for this outcome. Because previous research into sprawl has found that less sprawling areas have more crashes but less severe crashes, we disaggregate this crash analysis into KSI and non-KSI crashes.

We examined spatial error models to account for spatial autocorrelation, however, the spatial error component of these models was not statistically significant, suggesting that spatial autocorrelation is not a major effect for per-capita crash rates. Therefore, we used Tobit models to account for the non-negative nature of our dependent variable.

Tobin (1958) proposed the Tobit model or censored regression model. In this model, the regression is obtained by allowing right and left censorship while allowing the regression model to follow a linear formulation for middle values. The general form of the model is as follows:

$$
y_{i}^{*}=x_{i}^{\prime} \beta+\varepsilon_{i}
$$


Where $y_{i}^{*}$ defined as:

$$
y_{i}^{*}=\left\{\begin{array}{c}
y_{i} \text { if } a<y_{i}<b \\
a \text { if } y_{i} \leq a \\
b \text { if } y_{i} \geq b
\end{array}\right.
$$

$\varepsilon_{i}$ assumes that the error term is normally distributed with mean 0 and variance equals to $\sigma^{2}$. In this study, crashes per capita are the dependent variables, and $\beta$ are the coefficient for the variables $x_{i}^{\prime}$ presented in Table 4 and Table 5. The dependent variable crashes per capita is non-negative and therefore is "censored" for values that would potentially have been below 0 for a strictly linear model.

\section{$4 \quad$ Results}

The following family of six Tobit regressions displayed in Table 4 describes the relationship between accessibility to destinations and vehicular crashes per capita for Knoxville traffic analysis zones. Table 4 shows correlations between vehicular crashes per capita and zonal measures including accessibility, other built environmental measures, and demographic measures. Each variable's statistical significance is indicated and the overall model fit is measured through the Akaike information criterion (AIC). Only the 10-minute job accessibility measures are statistically significantly correlated with (at the $1 \%$ level) vehicle crashes per capita; this relationship is negative as expected. For 20-minutes job accessibility, the relationship is not statistically significant, while for 30-minute job accessibility, the direction of the relationship is reversed, in a positive direction, but not significant. Of note, the regional area of KRTM is small enough that most destinations are accessible from central TAZs within 30 minutes, which means that 30-minute job accessibility has a smaller coefficient of variation (0.634) than the more limitedscope 10 and 20 -minute thresholds $(10$ minutes $=0.841 ; 20$ minutes $=0.879)$.

In addition, when controlling for other built environment variables, 10 -minute accessibility to jobs becomes insignificant. Specifically, when the percentage of pay parking and the percentage of sidewalk coverage is controlled for, 10-minute accessibility to jobs no longer has a statistically significant relationship with vehicle crashes per capita. Meanwhile, the percentage of pay parking has a significant and negative relationship at the $\mathrm{p}<.001$ level and the percentage of sidewalk coverage has a significant and negative relationship at the $\mathrm{p}<.01$ level. The significance of these two variables suggests that built environments that discourage driving and provide safe facilities for walking may reduce vehicle-related crashes.

When examining specific job types as destinations, 10-minute retail job accessibility $(\mathrm{p}<.05)$ and 10 -minute service job accessibility $(\mathrm{p}<.001)$ both have a negative, statistically significant relationship with vehicle crashes per capita.

Control variables usually perform as expected, though many are not statistically significant. The population of university students has a consistent, negative, and significant relationship with crashes per capita, as expected, because university students typically drive less than other adults. Vehicles per capita is not statistically significant except for Model 4, where it is negatively correlated with crashes per capita $(\mathrm{p}<.05)$, an unexpected result; higher vehicle ownership is presumably related to higher amounts of driving. Median incomes, the percentage of school children, and the percentage of households with seniors do not have a significant effect on vehicle crashes per capita.

Next, we turn to the relationships demonstrated with accessibility to VMT on roadways in Table 5. Accessibility to VMT_FA (VMT on arterials and freeways) has a statistically significant and positive relationship with total crashes of all types (all injury levels, all modes) for 30-minute travel time thresholds, but not for 10 or 20-minute time thresholds. Examining specific crash types, 30-minute VMT_FA accessibility are significantly and positively related to both killed and serious injury type (KSI) crashes 
and to non-KSI crashes.

Surprisingly, accessibility to VMT on local roads has a negative association with total crashes per capita in Models 8 and 9, a negative association with KSI crashes in Model 12, and a negative association with non-KSI crashes in Models 14 and 15. We expect that this is due to the high correlation between accessibility to local road VMT and accessibility to total employment $(\rho=0.97)$.

Since we are here considering all crash types, not just vehicle crashes, the results are somewhat different than the previous regressions Percent of paid parking is negatively related to crashes per capita in all models; this variable may be capturing the diminished need for travel in urban locations. Percent of sidewalk coverage is negatively related to crashes per capita in all models, with sidewalks possibly reducing the occurrence of pedestrian crashes in particular. Vehicles per household is here typically has no relationship to crashes per capita, save for Model 1 and Model 13 where it is negative. Average median household income, on the other hand, is negatively related to crashes of all types. This is not unexpected because areas with lower-income households have frequently been associated with more crashes. The number of university students in a TAZ is associated with lower crashes per capita in models 7-9 and 1315.The percentage of households with seniors is negatively related to crashes per capita for Models 7,8 , 13 , and 14 , which corresponds with the expectations that seniors travel less on average than other adults.

Table 4. Model results for accessibility to destinations and vehicular crashes per capita

\begin{tabular}{|c|c|c|c|c|c|c|}
\hline & Model 1 & Model 2 & Model 3 & Model 4 & Model 5 & Model 6 \\
\hline & \multicolumn{6}{|c|}{ Accessibility Variables } \\
\hline $\begin{array}{l}\text { Employment Accessibility } \\
\text { (10-minute) }\end{array}$ & $-2.89 \mathrm{E}-04^{* * *}$ & & & $-1.11 \mathrm{E}-04$ & & \\
\hline $\begin{array}{l}\text { Employment Accessibility } \\
\text { (20-minute) }\end{array}$ & & $-1.6 \mathrm{E}-05$ & & & & \\
\hline $\begin{array}{l}\text { Employment Accessibility } \\
\text { (30-minute) }\end{array}$ & & & $1.90 \mathrm{E}-05$ & & & \\
\hline $\begin{array}{l}\text { Retail Employment Accessibility } \\
\text { (10-minute) }\end{array}$ & & & & & $-8.2 \mathrm{E}-04^{*}$ & \\
\hline \multirow{2}{*}{$\begin{array}{l}\text { Service Employment Accessibility } \\
\text { (10-minute) }\end{array}$} & & & & & & $-4.45 \mathrm{E}-04^{* * *}$ \\
\hline & \multicolumn{6}{|c|}{ Other Built Environment Variables } \\
\hline Percent Pay Parking & & & & $-272^{* * *}$ & & \\
\hline \multirow[t]{2}{*}{ Percentage of Sidewalk Cover-age } & & & & $-16.2^{* * *}$ & & \\
\hline & \multicolumn{6}{|c|}{ Socio-Demographic Variables } \\
\hline Vehicles per Household & -8.1 & 1.97 & 7 & $-9.98^{*}$ & -2.69 & -7.85 \\
\hline $\begin{array}{l}\text { Average Median Household } \\
\text { Income }\end{array}$ & -0.308 & -0.547 & -1.26 & -0.702 & -0.337 & -0.351 \\
\hline Percent K-12 students & 0.00558 & 0.00591 & 0.00607 & 0.00559 & 0.00599 & 0.00548 \\
\hline University Students & $-17.6^{* * *}$ & $-18.9^{* * *}$ & $-19.4^{* * *}$ & -8.4 & $-18.8^{* * *}$ & $-17.1^{* * *}$ \\
\hline $\begin{array}{l}\text { Percent of Households with } \\
\text { Seniors }\end{array}$ & -22 & -5.88 & 5.02 & $-30.5^{*}$ & -11.4 & -22.4 \\
\hline Constant & $157^{* * *}$ & $132^{* * *}$ & $119^{* * *}$ & $167^{* * *}$ & $143^{* * *}$ & $157^{* * *}$ \\
\hline $\mathrm{N}$ & 988 & 988 & 988 & 988 & 988 & 988 \\
\hline AIC & -3724.7 & -3714.7 & -3718.2 & -3772.1 & -3717.3 & -3726.1 \\
\hline
\end{tabular}

N.B.: Dependent variable in all cases is vehicular crashes per capita counted at the location of residence. ${ }^{* * *} \mathrm{p}<.001 ;{ }^{* *} \mathrm{p}<.01 ;{ }^{*} \mathrm{p}<.05$ 
Table 5. Model results for accessibility to VMT and total residential crashes per capita

\begin{tabular}{|c|c|c|c|c|c|c|c|c|c|}
\hline & Model 7 & Model 8 & Model 9 & Model 10 & Model 11 & Model 12 & Model 13 & Model 14 & Model 15 \\
\hline Crash Type & All & All & All & KSI & KSI & KSI & Non-KSI & Non-KSI & Non-KSI \\
\hline & \multicolumn{9}{|c|}{ Accessibility Variables } \\
\hline $\begin{array}{l}\text { VMT_L Acces- } \\
\text { sibility } \\
\text { (10-minute) }\end{array}$ & -.317 & & & -0.0295 & & & -0.273 & & \\
\hline $\begin{array}{l}\text { VMT_L_Acces- } \\
\text { sibility } \\
\text { (20-minute) }\end{array}$ & & $-.165^{*}$ & & & $-6.14 \mathrm{E}-03$ & & & $-.147^{*}$ & \\
\hline $\begin{array}{l}\text { VMT_L_Acces- } \\
\text { sibility } \\
\text { (30-minute) }\end{array}$ & & & $-.146^{* * *}$ & & & $-9.56 \mathrm{E}-03^{*}$ & & & $-.136^{* * *}$ \\
\hline $\begin{array}{l}\text { VMT_FA Acces- } \\
\text { sibility } \\
\text { (10-minute) }\end{array}$ & -0.317 & & & $-5.16 \mathrm{E}-03$ & & & -0.0168 & & \\
\hline $\begin{array}{l}\text { VMT_FA Acces- } \\
\text { sibility } \\
\text { (20-minute) }\end{array}$ & & 0.0282 & & & 3.64E-04 & & & 0.0272 & \\
\hline \multirow{2}{*}{$\begin{array}{l}\text { VMT_FA Acces- } \\
\text { sibility } \\
\text { (30-minute) }\end{array}$} & & & $.037^{* * *}$ & & & $2.95 \mathrm{E} 03^{*}$ & & & $0.0356^{* * *}$ \\
\hline & \multicolumn{9}{|c|}{ Other Built Environment Variables } \\
\hline \% Pay Parking & $-436^{* * *}$ & $-451^{* * *}$ & $-468^{* * *}$ & $-37.4^{* * *}$ & $-38.8^{* * *}$ & $-41.1^{* * *}$ & $-383^{* * *}$ & $-396^{* * *}$ & $-411^{* * *}$ \\
\hline \multirow{2}{*}{$\begin{array}{l}\% \text { of Sidewalk } \\
\text { Coverage }\end{array}$} & $-14.9^{*}$ & $-16.8^{*}$ & $-16.6^{*}$ & $-1.8^{*}$ & $-2.12^{* *}$ & $-2.12^{* *}$ & $-14.3^{*}$ & $-15.8^{*}$ & $-15.5^{*}$ \\
\hline & \multicolumn{9}{|c|}{ Socio-Demographic Variables } \\
\hline $\begin{array}{l}\text { Vehicles per House- } \\
\text { hold }\end{array}$ & $-16.6^{*}$ & -11.4 & -8.67 & -0.516 & -0.144 & 0.501 & $-16.2^{*}$ & -11.4 & -8.98 \\
\hline $\begin{array}{l}\text { Median Household } \\
\text { Income ( } \$ 10 \mathrm{Ks})\end{array}$ & $-2.96^{* *}$ & $-3.5^{* * *}$ & $-4.09^{* * *}$ & $-.754^{* * *}$ & $-.77^{* * *}$ & $-.877^{* * *}$ & $-2.01^{*}$ & $-2.54^{* *}$ & $-3.12^{* * *}$ \\
\hline$\% \mathrm{~K}-12$ students & 0.00763 & 0.00787 & 0.0075 & $9.90 \mathrm{E}-05$ & $1.33 \mathrm{E}-04$ & $1.21 \mathrm{E}-04$ & 0.00776 & 0.00796 & 0.0076 \\
\hline University Students & $-13^{*}$ & $-12.8^{*}$ & $-13^{*}$ & -0.649 & -0.605 & -0.628 & $-12.3^{*}$ & $-12.2^{*}$ & $-12.4^{*}$ \\
\hline $\begin{array}{l}\% \text { of Households } \\
\text { with Seniors }\end{array}$ & $-48^{* *}$ & $-38^{*}$ & -32.1 & -3.08 & -2.23 & -0.954 & $-42.2^{* *}$ & $-33.1^{*}$ & -27.7 \\
\hline _cons & $248^{* * *}$ & $238^{* * *}$ & $233^{* * *}$ & $38.4^{* * *}$ & $38.6^{* * *}$ & $38.4^{* * *}$ & $222^{* * *}$ & $213^{* * *}$ & $209^{* * *}$ \\
\hline $\mathrm{N}$ & 988 & 988 & 988 & 988 & 988 & 988 & 988 & 988 & 988 \\
\hline AIC & 10572 & 10570 & 10563 & 6290 & 6294 & 6290 & 10396 & 10394 & 10385 \\
\hline
\end{tabular}

N.B.: Dependent variable in all cases is crashes counted at the location of residence.

${ }^{* * *} \mathrm{p}<.001 ;{ }^{* *} \mathrm{p}<.01 ;{ }^{*} \mathrm{p}<.05 ; . \mathrm{p}<.10$ 


\section{Discussion}

Both hypotheses about the relationship between crashes per capita and accessibility to destinations measured from a person's location of residence were at least partially confirmed. Accessibility to destinations is in some cases negatively related to vehicular crashes. Accessibility to VMT is in most cases positively related to total crashes.

The accessibility travel time threshold appears to differ for these two effects. The effect of accessibility to employment destinations on exposure appears to be strongest at the smallest travel time threshold of 10 minutes. The more destinations that are available within a 10-minute drive, the less driving is required for persons on average, and therefore vehicle-related exposure is reduced. It is possible that these high-auto-accessibility areas also offer greater non-motorized or transit accessibility, though our analysis did not measure these effects. Accessibility to freeway and arterial VMT (VMT_FA), on the other hand, has its strongest effect at the 30-minute travel time threshold. Presumably, this larger travel time threshold (30 minutes) appropriately measures the ambient level of background traffic surrounding the average person's activity space. Because various types of accessibility are often highly correlated, it is likely that these two effects - accessibility to destinations and accessibility to VMT—are interfering with the measurement of each other, reducing each effects' statistical significance.

Although accessibility is here operationalized as accessibility to the total number of jobs, other destination's measures are examined as well. We also found accessibility to service jobs and accessibility to retail jobs both had a negative statistical relationship with vehicular crashes.

When other built environment measures were controlled for, the effect of accessibility to jobs became no longer statistically significant. Namely, when the percentage of pay parking and the percentage of sidewalk coverage were controlled for, destination accessibility lost its statistical significance. Because many measures of the built environment that distinguish urban from suburban/rural environments are highly correlated, it is often difficult to tell which variable or variables represent the causal mechanism for the observed built environment correlations. The data here are ambiguous about destination accessibility's causal effect in reducing vehicular crashes per capita.

The relationship between accessibility to VMT and higher crash rates is also consistent with our hypothesis. In particular, higher accessibility to high VMT streets correlates with greater amounts of traffic in the ambient environment. This is revealed by a higher number of crashes per capita for all modes as exposure to high-VMT environments increases. Both KSI crashes and non-KSI crashes displayed a similar pattern of increasing in high-VMT environments.

The safety implications of increased accessibility are therefore complex. To the extent that increased accessibility reduces the total distance spent driving or traveling by other modes, people may experience a safety benefit. Bringing origins and destinations closer together could reduce crashes by reducing vehicular exposure. However, locating people in high accessibility areas also may mean exposing them to environments with higher levels of traffic. Therefore, people who live in high accessibility environments may have to contend with higher levels of ambient traffic in their neighborhoods and activity spaces. This suggests the importance of improving safety in areas with high residential density and/or high levels of pedestrian activity because these benefits would be experienced by a large number of travelers.

Further research could examine the effect of accessibility on crashes more closely in several ways. First, more refined measures of destination accessibility are possible, such as those which take into account each destination's trip-attractiveness more precisely. For example, each job type could be weighted in accordance with its ability to attract trips, creating a trip attractiveness accessibility measure for each zone (Ortuzar \& Willumsen, 2011).

Likewise, the relationship between VMT accessibility and ambient traffic exposure could be further 
explored. A gravity-style VMT accessibility measure might better capture the average person's exposure to VMT in their environment.

This study between accessibility and safety examines a relatively auto-dependent and smaller metropolitan area, Knoxville, Tennessee. The relationship between residential accessibility, exposure, and crash rates per capita might vary significantly in other metropolitan areas with higher shares of transit, walking, and bicycling modes. Higher accessibility might have a greater effect on reducing vehicular travel in metropolitan areas with stronger modal alternatives.

\section{Conclusion}

This paper examines the potential relationship between a household's accessibility at its residential location and the likelihood that such a household will be in a crash over a three-year period. Traffic analysis zones are the unit of analysis with all built environment, socio-demographic, accessibility, and crash data calculated for TAZs. Two potential relationships are explored. First, higher accessibility to destinations has been related to lower household vehicle miles traveled and therefore is expected to reduce vehicular crashes. This effect is confirmed for 10-minute accessibility to jobs by auto, but the significance of the effect disappears when other built environment variables are accounted for. Second, higher accessibility to vehicle miles traveled on major roadways (arterials and freeways) is expected to be associated with more crashes of all types. This positive relationship between accessibility to population and total crashes is found for 30-minute accessibility to freeway and arterial VMT by auto. The positive relationship holds for both KSI and non-KSI crashes.

Accessibility, therefore, appears to have two contrary effects on household crashes; it reduces the amount of vehicular exposure by allowing households to drive and travel less but increases the amount of ambient traffic in the surrounding built environment. High-accessibility locations might be safer if such locations allowed a shift away from vehicular modes because then accessibility could reduce travelrelated exposure without increasing exposure to ambient traffic.

As far as the authors know, there is no previous peer-reviewed research that systematically explores the relationship between residential, place-based accessibility and the likelihood of being in a crash. Further analysis of this relationship by other researchers, employing a wider range of accessibility measures and examining alternative metropolitan areas, is encouraged. 


\section{References}

Abdel-Aty, M., Pande, A., Lee, C., Das, A., Nevarez, A., Darwiche, A., \& Devarasetty, P. (2009). Reducing fatalities and severe injuries on Florida's high-speed multi-lane arterial corridors: Part I, preliminary severity analysis of driver crash involvements, final report, April 2009. Orlando, FL: University of Central Florida, Center for Advanced Transportation Systems Simulation. Retrieved from http://ntl.bts. gov/lib/31000/31500/31520/FDOT_BD548-22_rpt_PART_I.pdf

Ahlfeldt, G. (2011). If Alonso was right: Modeling accessibility and explaining the residential land gradient. Journal of Regional Science, 51, 318-338. doi.org/10.1111/j.1467-9787.2010.00694.x

Boisjoly, G., \& El-Geneidy, A. M. (2017). How to get there? A critical assessment of accessibility objectives and indicators in metropolitan transportation plans. Transport Policy, 55, 38-50. doi. org/10.1016/j.tranpol.2016.12.011

Chen, P., \& Shen, Q. (2016). Built environment effects on cyclist injury severity in automobile-involved bicycle crashes. Accident Analysis \& Prevention, 86, 239-246. doi.org/10.1016/j.aap.2015.11.002

Chicago Metropolitan Agency for Planning. (2008). Preferred regional scenario. Chicago: Chicago Metropolitan Agency for Planning.

Ewing, R., \& Cervero, R. (2010). Travel and the built environment-A meta-analysis. Journal of the American Planning Association, 76, 265-294. doi.org/10.1080/01944361003766766

Ewing, R., \& Dumbaugh, E. (2009). The built environment and traffic safety: A review of empirical evidence. Journal of Planning Literature, 23(4), 347-367. doi.org/https://doi. org/10.1177/0885412209335553

Ewing, R., Hamidi, S., \& Grace, J. B. (2016a). Urban sprawl as a risk factor in motor vehicle crashes. Urban Studies, 53(2), 247-266. doi.org/10.1177/0042098014562331

Ewing, R., Hamidi, S., \& Grace, J. B. (2016b). Urban sprawl as a risk factor in motor vehicle crashes. Urban Studies, 53(2), 247-266. doi.org/10.1177/0042098014562331

Geurs, K. T., \& Van Wee, B. (2004). Accessibility evaluation of land-use and transport strategies: Review and research directions. Journal of Transport Geography, 12(2), 127-140. doi.org/10.1016/j. jtrangeo.2003.10.005

Handy, S. L., \& Niemeier, D. A. (1997). Measuring accessibility: An exploration of issues and alternatives. Environment and Planning A, 29, 1175-1194.

Hansen, W. G. (1959). How accessibility shapes land use. Journal of the American Institute of Planners, $12,73-76$.

Heyman, A., Law, S., \& Berghauser Pont, M. (2018). How is location measured in housing valuation? A systematic review of accessibility specifications in hedonic price models. Urban Science, 3(1), 3. doi.org/10.3390/urbansci3010003

Hezaveh, A. M., Arvin, R., \& Cherry, C. R. (2019). A geographically weighted regression to estimate the comprehensive cost of traffic crashes at a zonal level. Accident Analysis \& Prevention, 131(June), 15-24. doi.org/10.1016/j.aap.2019.05.028

Kim, K., Pant, P., \& Yamashita, E. (2010). Accidents and accessibility: Measuring influences of demographic and land-use variables in Honolulu, Hawaii. Transportation Research Record, 2147, 9-17. doi.org/10.3141/2147-02

Lochmueller \& Associates, I. (2012). Knoxville regional travel model update 2012 model development and validation report. Evansville, IN: Lochmueller \& Associates.

Lucy, W. H. (2003). Mortality risk associated with leaving home: Recognizing the relevance of the built environment. American Journal of Public Health, 93(9), 1564-1569. Retrieved from https://ajph. aphapublications.org/doi/pdfplus/10.2105/AJPH.93.9.1564 
Marshall, W. E., \& Garrick, N. W. (2011). Does street network design affect traffic safety? Accident Analysis and Prevention, 43(3), 769-781. doi.org/10.1016/j.aap.2010.10.024

Merlin, L. A., Levine, J., \& Grengs, J. (2018). Accessibility analysis for transportation projects and plans. Transport Policy, 69, 35-48. doi.org/10.1016/j.tranpol.2018.05.014

Miller, H. J. (1991). Modelling accessibility using space-time prism concepts within geographical information systems. International Journal of Geographic Information Science, 5, 287-301.

Mohamed, R., vom Hofe, R., \& Mazumder, S. (2014). Jurisdictional spillover effects of sprawl on injuries and fatalities. Accident Analysis \& Prevention, 72, 9-16. doi.org/10.1016/j.aap.2014.05.028

OECD, \& ITF. (2016). Road safety annual report 2016. Paris: International Transport Forum. Retrieved from http://dx.doi.org/10.1787/irtad-2016-en

Ortuzar, J. de D., \& Willumsen, L. G. (2011). Modeling transport (4th ed.). Chichester, England: John Wiley \& Sons.

Owen, A., \& Levinson, D. M. (2015). Modeling the commute mode share of transit using continuous accessibility to jobs. Transportation Research Part A: Policy and Practice, 74, 110-122. doi. org/10.1016/j.tra.2015.02.002

Quddus, M. A. (2008). Modelling area-wide count outcomes with spatial correlation and heterogeneity: An analysis of London crash data. Accident Analysis \& Prevention, 40(4), 1486-1497. doi. org/10.1016/j.aap.2008.03.009

Retting, R. A., Ferguson, S. A., \& McCartt, A. T. (2003). A review of evidence-based traffic engineering measures designed to reduce pedestrian-motor vehicle crashes. American Journal of Public Health, 93(9), 1456-1463. doi.org/10.2105/AJPH.93.9.1456

Rothman, L., Buliung, R., Macarthur, C., To, T., \& Howard, A. (2014). Walking and child pedestrian injury: A systematic review of built environment correlates of safe walking. Injury Prevention, 20(1), 41-49. doi.org/10.1136/injuryprev-2012-040701

Santos, A., McGuckin, N., Nakamoto, H. Y., Gray, D., \& Liss, S. (2011). Summary of travel trends: 2009 National Household Travel Survey. Washington, DC: US Department of Transportaion.

Stevens, M. R. (2016). Does compact development make people drive less? Journal of the American Planning Association, 83(1), 7-18. doi.org/10.1080/01944363.2016.1240044

Stoker, P., Garfinkel-Castro, A. A., Khayesi, M., Odero, W., Mwangi, M. N., Peden, M., \& Ewing, R. (2015). Pedestrian safety and the built environment: A review of the risk factors. Journal of Planning Literature, 30(4), 377-392. doi.org/10.1177/0885412215595438

Tobin, J. (1958). Estimation of relationships for limited dependent variables. Econometrica: Journal of the Econometric Society, 26(1), 24-36.

Virginia Department of Transportation. (2017). Smart scale: Finding the right transportation projects for Virginia. Retrieved from http://vasmartscale.org/

Waddell, P. (2002). UrbanSim-Modeling urban development for land use, transportation, and environmental planning. Journal of the American Planning Association, 68, 297-314.

Wier, M., Weintraub, J., Humphreys, E. H., Seto, E., \& Bhatia, R. (2009). An area-level model of vehicle-pedestrian injury collisions with implications for land use and transportation planning. $A c-$ cident Analysis \& Prevention, 41(1), 137-145. doi.org/10.1016/j.aap.2008.10.001

Yeo, J., Park, S., \& Jang, K. (2015). Effects of urban sprawl and vehicle miles traveled on traffic fatalities. Traffic Injury Prevention, 16(4), 397-403. doi.org/10.1080/15389588.2014.948616 